\title{
Broodstock development, induced breeding and larval rearing of Indian pompano, Trachinotus mookalee, (Cuvier, 1832) - A new candidate species for aquaculture
}

\author{
Ritesh Ranjan*, Sekar Megarajan, Biji Xavier, Shubhadeep Ghosh, B. Santhosh, A. Gopalakrishnan \\ Regional Centre of ICAR-CMFRI, Visakhapatnam, Andhra Pradesh 530 003, India
}

A R T I C L E I N F O

\section{Keywords:}

Indian pompano

Broodstock

Induced breeding

Larval rearing

\begin{abstract}
A B S T R A C T
The present study describes the first trial on broodstock development, induced breeding and larval rearing of Indian pompano, Trachinotus mookalee. Indian pompano fingerlings were collected from wild and raised to adults having an average size of $2.84 \pm 0.10 \mathrm{~kg}$ weight and $47.6 \pm 1.43 \mathrm{~cm}$ length. These adult fishes were stocked in $125 \mathrm{t}$ capacity circular tank having re-circulatory facility for broodstock development. The fishes were fed with squid along with clam meat and matured in four months. Mature females with $>500 \mu \mathrm{m}$ ova and oozing males were selected in the ratio of 1:2 (female:male) and were induced with single dose of hCG at the rate of $350 \mathrm{IU} / \mathrm{kg}$ body weight. Three trials with same sex ratio and hormonal doses were tried. The fish spawned after $36-38 \mathrm{~h}$ of induction at a temperature $29 \pm 1{ }^{\circ} \mathrm{C}$. Eggs were collected and treated with iodophore and stocked in $1 \mathrm{t} \mathrm{FRP}$ tank for hatching. The eggs hatched out after $18-20 \mathrm{~h}$ of incubation at a temperature of $29 \pm 1{ }^{\circ} \mathrm{C}$. The overall fertilization and hatching rate was found to be $69 \pm 1.55 \%$ and $87.67 \pm 0.81 \%$, respectively. Larval rearing was carried out in $2 \mathrm{t}$ capacity fibre reinforced plastic (FRP) tanks using green water system. The newly hatched larvae was $2.12 \pm 0.02 \mathrm{~mm}$ in total length, with an oval shaped yolk sac of $0.55 \mathrm{~mm}^{2}$ and an oil droplet of $0.06 \mathrm{~mm}^{2}$ in area. The mouth opening was formed $40-46 \mathrm{~h}$ post hatch with mouth gape measuring $228.10 \pm 1.31 \mu \mathrm{m}$. A systematic and overlapping regime of live feed beginning from copepod nauplii, rotifer, Artemia nauplii and artificial pellet were utilized during larval rearing. Weaning of larvae to inert diet was started from $15^{\text {th }}$ day post hatching (DPH) onwards. Larvae started metamorphosis by $17^{\text {th }} \mathrm{DPH}$ onwards and was completed by $21^{\text {st }} \mathrm{DPH}$, when the larvae reached $27.33 \pm 0.10 \mathrm{~mm}$. The larval rearing protocol resulted in an average survival rate of $21.53 \pm 1.45 \%$ till complete metamorphosis. The present study showed T. mookalee to mature in captive conditions. The potential for induced spawning in captivity and larval rearing with a survival rate of $21.53 \%$ makes Indian pompano an excellent candidate for mariculture. This forms the first report of broodstock development, induced breeding and larval rearing of this species in captivity. The results of this study would facilitate mass scale seed production of Indian pompano in captivity, which is essential for its aquaculture.
\end{abstract}

\section{Introduction}

Selecting and studying new fish species suitable for breeding and seed production is essential for future development and diversification of the aquaculture industry. Several species of pompano (Trachinotus carolinus and T. blochii) are well recognised as promising species for mariculture due to their attractive appearance, fast and uniform growth rate, adaptability to culture environment, acceptability to formulated feed, firm white as well as tasty meat and high market demand. The broodstock development of Florida pompano (Trachinotus carolinus) and its seed production as well as farming technology has been well established in the USA during 1970s (McMaster et al. 2003). Artificial propagation techniques for Trachinotus blochii were fully developed in Taiwan during 1989 (Chang 1993; Cheng 1990). The aquaculture of pompano is successfully established in many Asia - Pacific countries like Taiwan and Indonesia.

Trachinotus mookalee (Indian pompano) is another species belonging to the family Carangidae (jacks and pompanos) which holds immense potential for the marine finfish aquaculture sector. It is a pelagic species which inhabits shallow coastal water (Smith-Vaniz 1984). It is distributed from the western Indian Ocean to the western Pacific Ocean. Indian pompano is reported to grow to a size of $90 \mathrm{~cm}$ in total length

\footnotetext{
* Corresponding author at: Scientist, Mariculture Division, Regional Centre of ICAR-CMFRI, Visakhapatnam, Andhra Pradesh 530 003, India.

E-mail address: rranjanfishco@gmail.com (R. Ranjan).
} 
(Randall 1995) and $8.1 \mathrm{~kg}$ body weight (Smith-Vaniz 1984). Under captivity, when grown in offshore cages, Indian pompano grew from $42.8 \mathrm{~g}$ to $969.90 \mathrm{~g}$ after 9 months of culture (Ranjan et al., 2017a). Indian pompano is caught sporadically in the commercial fishery and therefore its availability is rather scarce in the fish markets and hence the increasing demand can only be met through aquaculture.

Though the seed production and farming technology for the various pompano species has been established much earlier (Chang 1993; Cheng 1990; Gopakumar et al. 2012; Hoff et al. 1972, 1978a, 1978b), there is no published literature available on the broodstock development, induced breeding and seed production of Indian pompano. Keeping all this in view and its immense growth potential, the present study was aimed at broodstock development, induced breeding and larval rearing of Indian pompano, Trachinotus mookalee for realizing its aquaculture potential.

\section{Materials and methods}

\subsection{Experimental animal}

Juveniles of Indian pompano $(45.10 \pm 2.50 \mathrm{~g})$ were collected off Visakhapatnam $\left(17^{\circ} 42.256^{\prime} \mathrm{N}\right.$ and $\left.83^{\circ} 18.838^{\prime} \mathrm{E}\right)$ along western Bay of Bengal using cast nets and were transported to hatchery of Visakhapatnam Regional Centre of Central Marine Fisheries Research Institute, Visakhapatnam, Andhra Pradesh (India). The collected juveniles $(45.10 \pm 2.50 \mathrm{~g})$ were raised to adults in 21 months of culture period having average size of $2.84 \pm 0.10 \mathrm{~kg}$ weight and $47.6 \pm 1.43 \mathrm{~cm}$ length for developing broodstock. During the culture period, salinity varied from 30 to $32 \mathrm{gL}^{-1}$, temperature and $\mathrm{pH}$ ranged between 27 and $30^{\circ} \mathrm{C}$ and 7.8-8.1, dissolved oxygen content, total ammonia nitrogen and nitrite varied from 4 to 5.7, 0.34-0.112 and $0.005-0.029 \mathrm{mgL}^{-1}$ respectively.

\subsection{Broodstock development in re-circulatory system}

A total of 18 fish (average size of $2.84 \pm 0.10 \mathrm{~kg}$ weight and $47.6 \pm 1.43 \mathrm{~cm}$ length) in sex ratio (female: male) of $1: 2$ were selected and stocked in $125 \mathrm{t}$ capacity circular RCC tank for broodstock development. The present experiment was carried out in tropical condition where the light and dark period varies almost equally. Natural photoperiod was followed during the experiment. The sex as well as gonadal maturity was assessed by live gonadal biopsy from 21 months onwards, when the fishes have grown to a size of $2.84 \mathrm{~kg}$, using flexible catheter of 1-mm inner and 2-mm outer diameter (feeding tube $\mathrm{CH}$ 6, procured from local medical shop, Visakhapatnam). Each fish was individually tagged with a tag transponder (PIT TAG FS 2001) for identification and to maintain their track record of gonadal development. The tank was connected with different components of recirculatory aquaculture system (RAS) such as rapid sand filter to remove suspended solids, a $500 \mathrm{~L}$ protein skimmer to eliminate dissolved solids and a $2 \mathrm{t}$ capacity tank with $500 \mathrm{~kg}$ molluscan shells and bioballs used as biological filter to reduce biochemical waste. Entire water of the tank was re-circulated $300 \%$ per day, and loss of water was topped up at the rate of $3 \%$ per day to compensate the loss due to protein skimmer and backwashes of rapid sand filter (Ranjan et al., 2017b).

\subsection{Feeding}

The fishes were continually fed on fresh squid and clam meat twice $(0900$ and $1530 \mathrm{~h})$ a day till satiation. Moreover, various vitamins namely, vitamin A (25,000 IU, USV limited, Nani Daman, India), vitamin B-complex (Pfizer, India), vitamin C ( $500 \mathrm{mg}$; Abbott Healthcare Pvt. Ltd., Thane, Maharashtra, India), vitamin E (400 mg) (Merck, Goa, India) and vitamin-mineral mix (Agrimin Forte, Virbac Animal Health India Pvt. Ltd., Mumbai, Maharashtra, India) were supplemented twice a week along with the feed to avoid any possible nutritional deficiencies in their diet. These vitamin and mineral tablets was inserted in squid and fed to the fishes. Proximate composition of fresh squid revealed it to consist of $81.09 \%$ moisture, $13.19 \%$ crude protein, $0.85 \%$ crude fat, $1.52 \%$ ash and $3.35 \%$ carbohydrate. Proximate composition of clam meat revealed it to consist of $79.75 \%$ moisture, $12.83 \%$ crude protein, $2.24 \%$ crude fat, $3.72 \%$ ash and $1.46 \%$ carbohydrate. The excess feed was removed from the bottom of the tank after $30 \mathrm{~min}$.

\subsection{Assessment of gonadal development}

The progression of gonadal maturation of female was evaluated by means of oocyte diameter distribution. The female and male fish were assessed for gonadal maturation by cannulation using catheter. During early morning, the fish were anaesthetized with $200 \mathrm{ppm}$ of 2-phenoxyethanol for $2 \mathrm{~min}$ or until the opercular movement was significantly reduced. Then the fishes were cannulated to collect gonadal tissue. The collected gonadal tissues were examined under a trinocular microscope (Nikon, Japan) with in-built photo-imaging system for morphometric analysis. The gonadal assessment for all female fish was carried out at 15-day intervals by assessing the percentage frequency of cannulated ova of different sizes.

\subsection{Assessment of physico-chemical parameters}

The physiochemical parameters such as salinity, temperature, dissolved oxygen, free carbon dioxide, total ammonia nitrogen (TAN), nitrite, alkalinity and $\mathrm{pH}$ of the tank water were analyzed weekly. The salinity and temperature were measured using a digital refractometer.

(Atago India Instrument Private Ltd., Mumbai, Maharashtra, India) and thermometer respectively. Water $\mathrm{pH}$ was measured with the help of a probe-based $\mathrm{pH}$ meter (Eutech, Thermofisher Scientific, Mumbai, India). Dissolved oxygen, ammonia, nitrite and alkalinity were estimated following the standard methods of APHA (1998). The data of physico-chemical parameters for the entire experimental period were expressed as mean \pm SEM.

\subsection{Spawning induction and egg collection}

Three induction trails with the same sex ratio were attempted for induced breeding of Indian pompano during three different months. Matured females containing vitellogenic oocytes with mean diameter larger than $500 \mu \mathrm{m}$ and oozing males were selected for induction. The sex ratio (female to male) for induced spawning trial was 1:2. Both females and males were injected with single dose of human chorionic gonadotropin (hCG; manufactured by Bharat Serum and Caccines Limited, Ambernath (E), Maharashtra, India) at the rate of $350 \mathrm{IU} \mathrm{kg}^{-1}$ body weight (BW) and were stocked in the same tank for spawning. This hormonal dose was selected on the basis of our previous unpublished work and on the work carried out in another species of pompano (Gopakumar et al. 2012). The spawned eggs from broodstock tank were collected by passing the surface water through an egg-collecting chamber fitted with a hapa of $500 \mu \mathrm{m}$. The eggs get sieved in the hapa, and the accumulated eggs were collected through a scoop net and treated with $20 \mathrm{ppm}$ iodophore for $10 \mathrm{~min}$ and were finally stocked in $1 \mathrm{t}$ FRP tank for hatching. Total number of eggs from each spawning was counted by taking $10 \mathrm{ml}$ of samples from five different places in $1 \mathrm{t}$ FRP tank. Before taking samples for counting, the eggs were evenly distributed by mixing the water gently.

\subsection{Egg quality}

Fertilization and hatching rate of the three spawning trails were estimated and used as indicators for egg quality. Estimation of fertilization rate was undertaken after $10 \mathrm{~h}$ of spawning but well before hatching. The fertilized eggs were differentiated from unfertilized eggs based on the colour. The embryonic development in fertilized eggs 


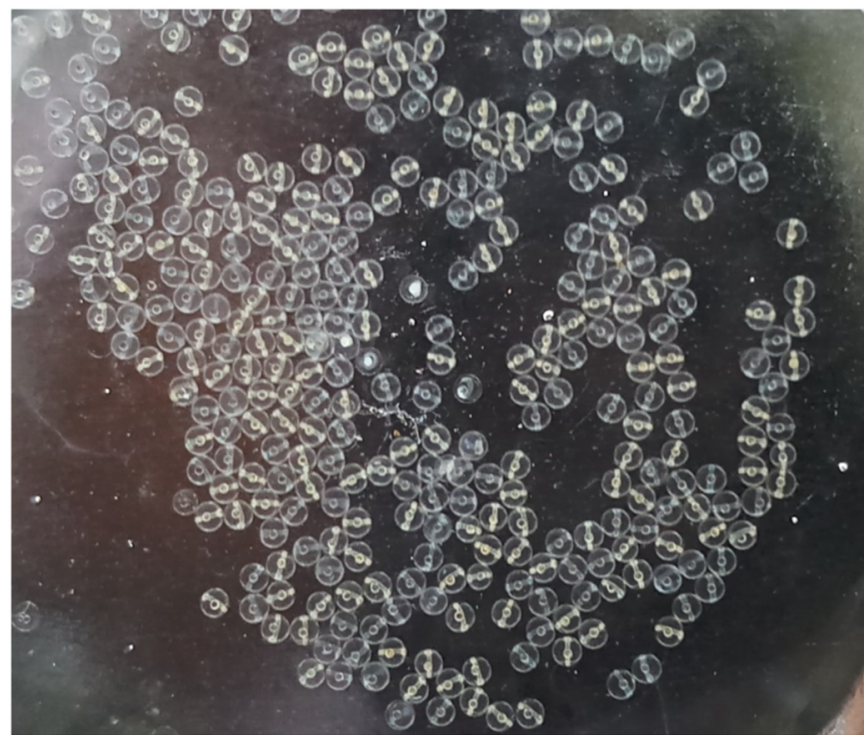

Fig. 1. Fertilized eggs of Indian pompano having a transparent appearance.

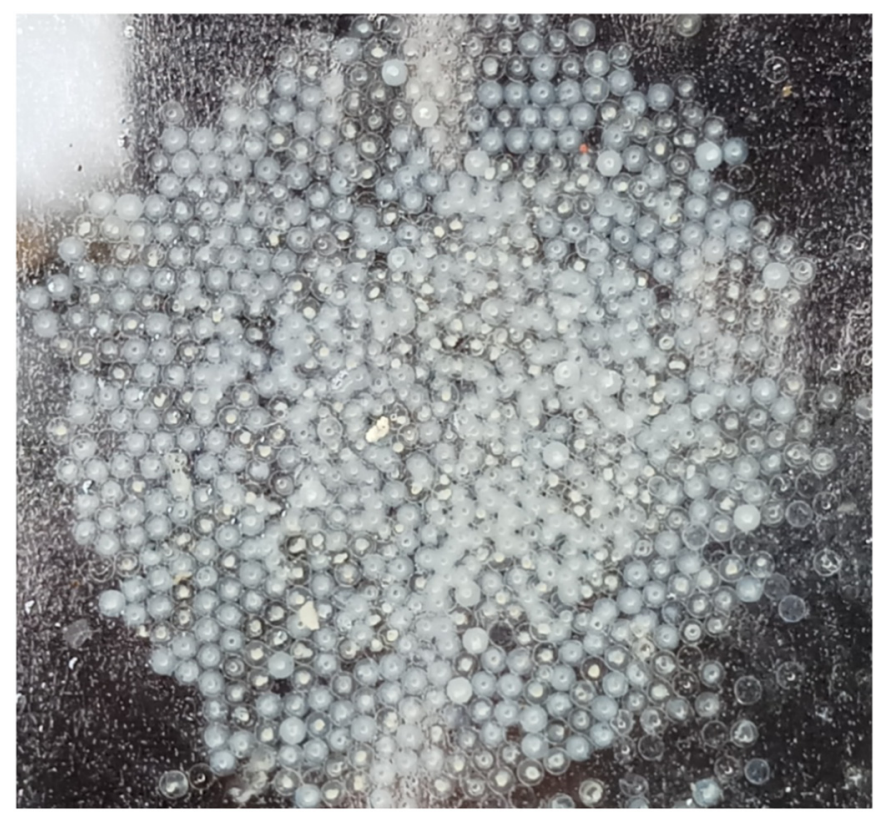

Fig. 2. Unfertilized eggs of Indian pompano having an opaque appearance.

makes them transparent (Fig. 1), whereas unfertilized eggs are opaque (Fig. 2). The numbers of fertilized and unfertilized eggs were counted. Fertilized eggs were counted in the same manner as that for counting total numbers of eggs. The number of fertilized eggs was divided by total number of eggs and multiplied by 100 to obtain fertilization rate (\%). It must be noted that eggs which sank immediately after spawning were not collected, and, hence the fertilization rate could be slightly inflated. After hatching, the hatching rate was calculated by taking five samples by vertically immersing a PVC pipe in the hatching tank. Hatching rate (\%) was estimated as the number of hatched out larvae divided by number of fertilized eggs stocked in hatching tanks, multiplied by 100 . The fertilization rate and hatching rate were expressed as mean \pm SEM.

\subsection{Larval rearing}

The hatched out larvae were stocked in $2 \mathrm{t}$ circular FRP tank with $1 \mathrm{t}$ sea water at the rate of 10 numbers per liter in triplicate. The tank was provided with one central air stone with mild aeration. Larviculture was carried out using green water technique by employing different microalgae. A systemic and overlapping regime of different live foods such as copepod nauplii, rotifer, Artemia nauplii and artificial pellet were utilized during the larval rearing. The physiochemical parameters such as salinity, temperature, dissolved oxygen, total ammonia nitrogen (TAN) and nitrite of the tank water were estimated daily and maintained to the optimum level required for the larval rearing of marine finfish. The larval percentage survival (\%) was estimated as the number of metamorphosed larvae divided by the number of hatched out larvae stocked in larval rearing tanks, multiplied by 100 . The survival rate was expressed as mean \pm SEM.

\section{Result and discussion}

T. mookalee is a potential candidate species for mariculture possessing high economic value (Ranjan et al., 2017a, b). This work is the first to report on the gonadal maturation and broodstock development of this species under confined conditions. The present study is also the first report on developing standardized techniques for induced breeding and larval rearing of this species.

Our study indicated that female oocyte development in Indian pompano is synchronous batch-type. One set of eggs was seen to develop synchronously with similar size, ready to be spawned. Even before this set was spawned, immature oocytes were visible in the ovary samples. The numbers of immature oocytes was much higher than the mature oocytes. Some medium-sized maturing oocytes were also visible; however, their numbers were very few (Fig. 3). Similar to the present study, Lemos et al. (2011) reported synchronous oocytes development in plata pompano, Trachinotus marginatus collected from wild. The cytoplasmic inclusion bodies were observed in oocytes larger than $150 \mu \mathrm{m}$ in diameter and might be indicators of secondary growth of oocytes and beginning of vitellogenesis (Fig. 3b). The specific nature of these inclusions (lipid droplets, cortical alveoli or yolk granules etc) was not determined. The final stage of vitellogenesis was observed in oocytes larger than $350 \mu \mathrm{m}$, which is marked by large opaque mass in the oocytes (Fig. 3c.). The maximal vitellogenic oocyte diameter was $595 \mu \mathrm{m}$. Fish in the final stages of vitellogenesis with $>500 \mu \mathrm{m}$ were considered as mature (Fig. 4). The male became ripe after attaining $3.0 \mathrm{~kg}$ and were found to ooze milt on applying slight pressure to the abdomen. Similar to present study, several authors have reported $>$ $500 \mu \mathrm{m}$ ova size to be optimum for induction in other species of pompano viz., Trachinotus blochii (Gopakumar et al. 2012) and Trachinotus carolinus (Hoff et al. 1972; Weirich and Riley 2007). It is understood from earlier reports that fishes are prone to reproductive dysfunction when they are reared in captive conditions and various authors (Peter et al. 1993; Zohar 1988, 1989a, 1989b) have reported in several species of fishes that female fail to undergo final oocyte maturation in captive conditions. However in the present study, female underwent final oocyte maturation with an ova size of $>500 \mu \mathrm{m}$. This is due to optimal conditions provided to the fish in re-circulating tank as evident by the estimated values of the different physio-chemical water quality parameters (Table 1).

Successful induced spawning of different pompano species was reported earlier by using different doses of inducing hormone. Hoff et al. (1972) administered two doses of hCG (550 IU kg ${ }^{-1}$ and $275 \mathrm{IU} \mathrm{kg}^{-1}$ ) at 24-48 h of interval to T. carolinus. Juniyanto and Akbar (2008) used two doses of hCG (250 IU kg ${ }^{-1}$ ) with fibrogen $\left(50 \mathrm{IU} \mathrm{kg}^{-1}\right)$ in two days period, whereas Gopakumar et al. (2012) used a single dose of hCG ( $350 \mathrm{IU} \mathrm{kg}^{-1}$ ) for inducing spawning in T. blotchii. In the present study, single dose of hCG at the rate of $350 \mathrm{IU} \mathrm{kg}^{-1}$ body weight resulted in successful induced spawning of Indian pompano and spawning occurred within $36-38 \mathrm{~h}$ of induction at a temperature $29 \pm 1{ }^{\circ} \mathrm{C}$. Similar to the present study, authors (Gopakumar et al. 2012; Hoff et al. 1972; Juniyanto and Akbar, 2008; McMaster et al. 2003) have reported induced spawning of different pompano species after $30-48 \mathrm{~h}$ of first 

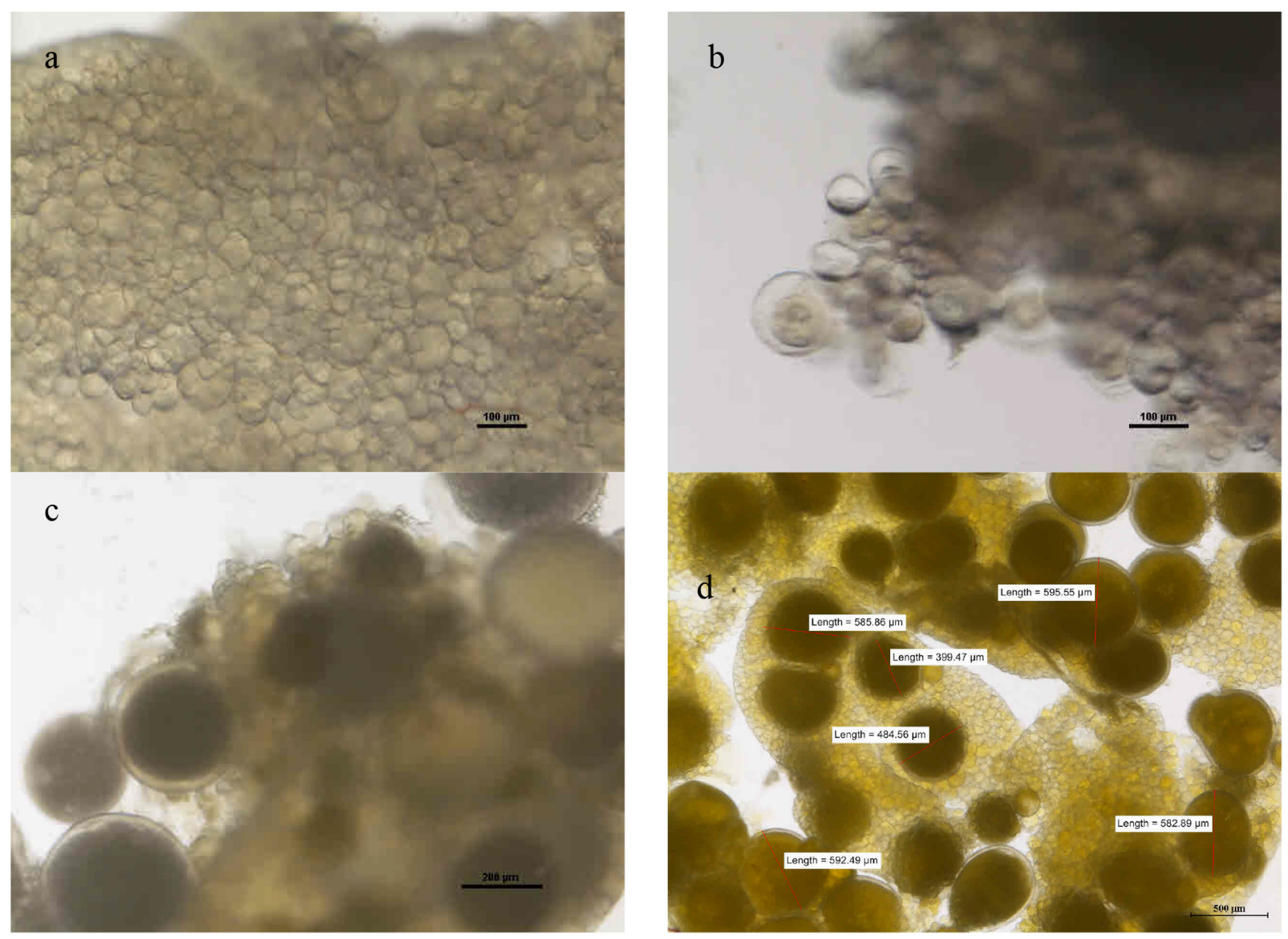

Fig. 3. Different maturity stages of Indian pompano female gonad (a. honeycomb stage oocytes of $<100 \mu \mathrm{m}$ diameter; b. Oocytes of $>100 \mu \mathrm{m}$ diameter with cytoplasmic inclusion bodies; c. oocytes of $>300 \mu \mathrm{m}$ diameter showing final stage of vittellogensis; d. Ready to induced gonadal tissue showing two sets of ova viz., one set ready to spawn and other just honeycomb stage).

injection. The latency period might be varying due to different hormonal doses used for induction as well as due to differences in water temperature and the species.

Total number of eggs spawned during the three trials ranged from 60,000 to 110,000 per female. The present study showed that size of the fertilized eggs of Indian pompano was slightly larger $(950-1000 \mu \mathrm{m})$ than that reported in Florida pompano $(870-1000 \mu \mathrm{m})($ McMaster et al. 2003) and silver pompano (800-850 $\mu \mathrm{m})$ (Juniyanto and Akbar, 2008).
This could be due to the varying nature of the species and use of different maturity stage of female for induction. The average fertilization rate obtained during the three trials was $69 \pm 1.55 \%$ with female and male sex ratio of 1:2 (Fig. 5). Different fertilization rates have been reported in different species of pompano by various authors. Main et al. (2005) reported a fertilization rate of $19.3-48.2 \%$ in Florida pompano with a sex ratio of 1:1. Juniyanto et al. (2008) reported $60-70 \%$ fertilization rate with a sex ratio of $1: 1$ and Gopakumar et al. (2012)

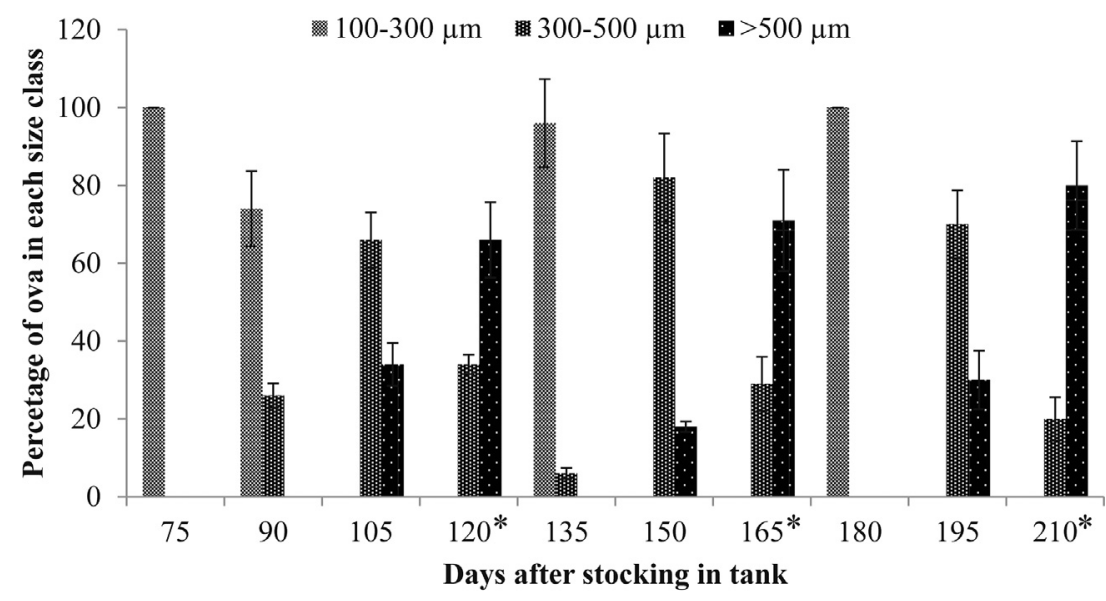

*induced with hCG for spawning

Fig. 4. Progression of gonadal maturation of female broodfish ( $n=6$; Ova size classes have been merged for easy interpretation of the graph and honeycomb stage oocytes were not taken in consideration while counting) *brooders were induced with hCG. 
Table 1

Physico-chemical parameters of the re-circulatory broodstock tank water during the experimental period.

\begin{tabular}{ll}
\hline Physico-chemical parameters & Value (Mean $\pm \mathrm{SE}$ ) \\
\hline Salinity $\left(\mathrm{gL}^{-1}\right)$ & $31.35 \pm 0.13$ \\
Temperature $\left({ }^{\circ} \mathrm{C}\right)$ & $29.33 \pm 0.25$ \\
Dissolved oxygen $\left(\mathrm{mgL}^{-1}\right)$ & $4.64 \pm 0.07$ \\
Free carbon dioxide $\left(\mathrm{mgL}^{-1}\right)$ & $0.18 \pm 0.01$ \\
Total ammonia nitrogen $\left(\mathrm{mgL}^{-1}\right)$ & $0.037 \pm 0.002$ \\
Nitrite $\left(\mathrm{mgL}^{-1}\right)$ & $0.003 \pm 0.00$ \\
Alkalinity $\left(\mathrm{mgL}^{-1}\right)$ & $102.40 \pm 2.04$ \\
pH & $7.98 \pm 0.04$ \\
\hline
\end{tabular}

arial $1 \square$ Trial $2 \square$ Trial 3

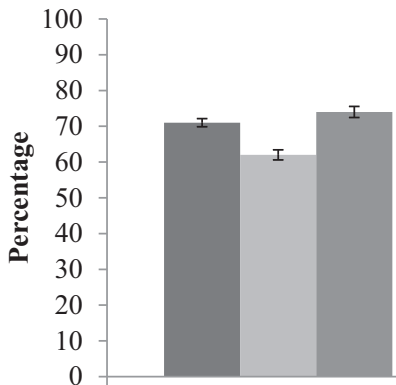

Fertilization rate

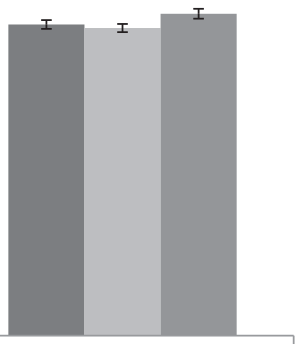

Hatching rate
Fig. 5. Fertilization rate (\%) of total collected eggs and hatching rate (\%) of fertilized eggs over the course of three spawning trials.

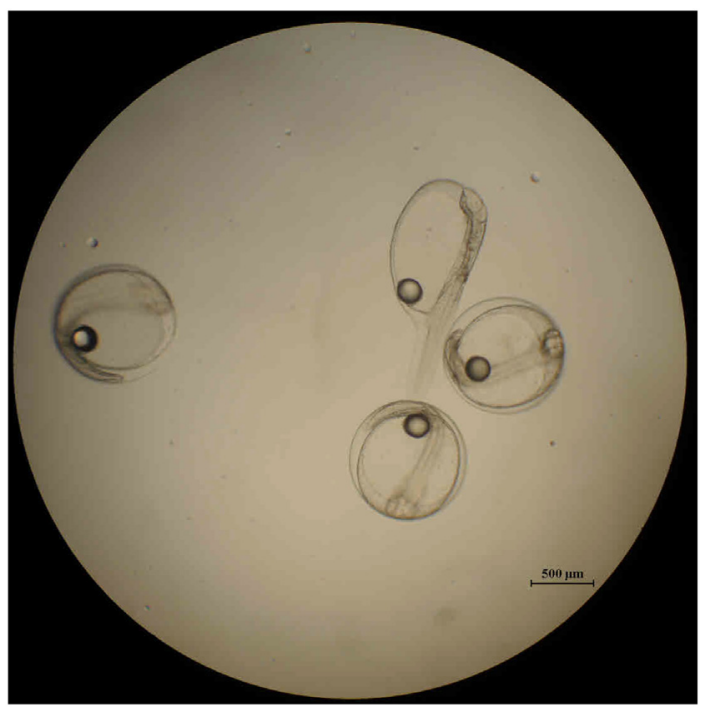

Fig. 6. Hatching of the eggs in progress.

reported $75-90 \%$ fertilization rate with a sex ratio of $1: 3$ in silver pompano. The fertilization rate varies with the sex ratio used in the spawning. The eggs hatched after $18-20 \mathrm{~h}$ of incubation at a temperature of $29 \pm 1{ }^{\circ} \mathrm{C}$ (Fig. 6). The average hatching rate during the three trials was estimated as $87.67 \pm 0.81 \%$ (Fig. 5). Similarly to the present study, Weirish and Riley (2007) estimated a hatching rate of $71.3-95.4 \%$ in Florida pompano.

The morphological development of T. mookalee prior to metamorphosis was similar to that of other pompano species such as T. blochii (Abdul Nazar et al. 2012). The newly hatched larvae were $2.12 \pm 0.02 \mathrm{~mm}$ in total length with an oval shaped yolk sac of $0.55 \mathrm{~mm}^{2}$ and an oil droplet of $0.06 \mathrm{~mm}^{2}$ in area (Fig. 7). The body length increased to $2.58 \mathrm{~mm}$ on $1^{\text {st }} \mathrm{DPH}$ while the yolk sac decreased to

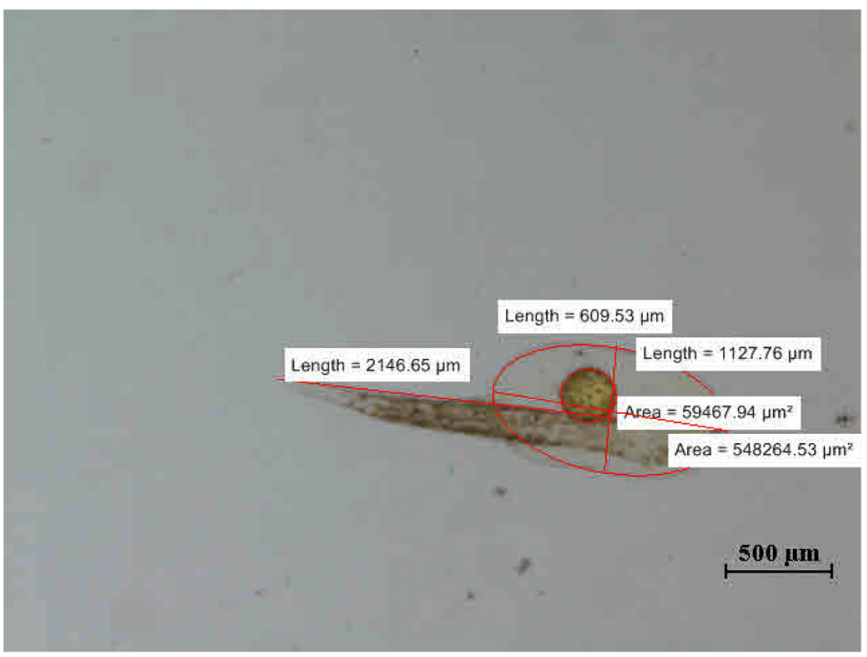

Fig. 7. Newly hatched larvae with different measurements.

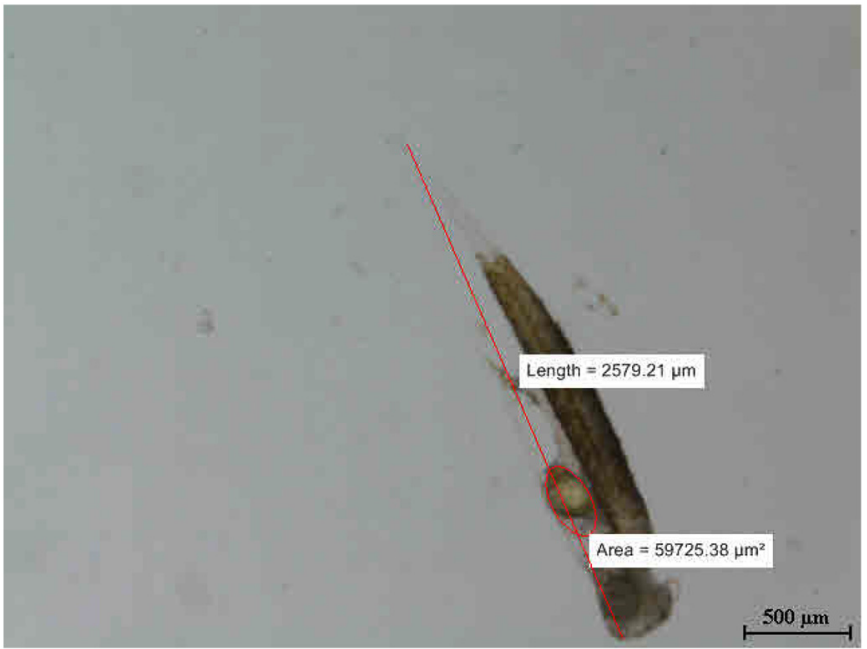

Fig. 8. First day post hatch larvae showing different measurements.

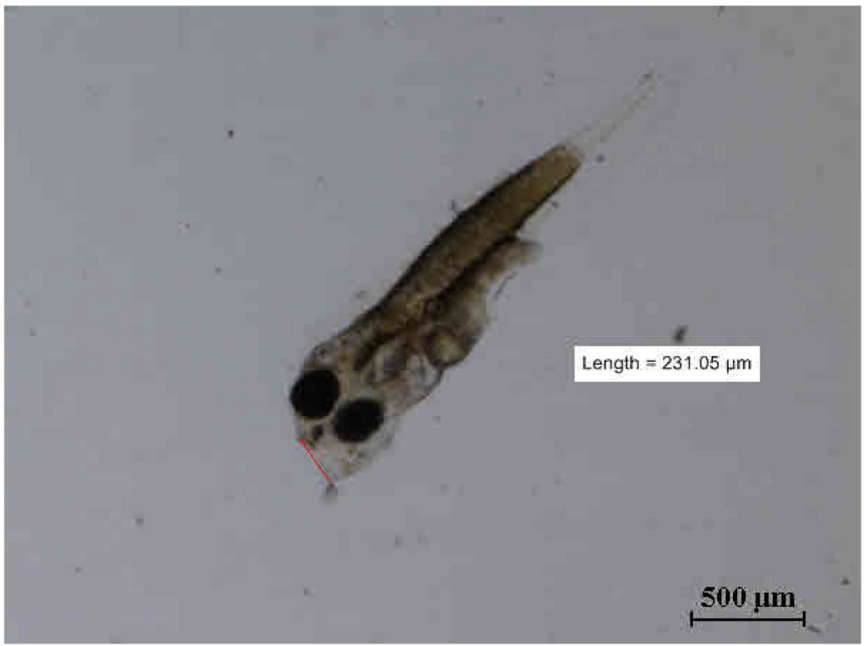

Fig. 9. Larvae $46 \mathrm{~h}$ post hatch showing mouth gape after mouth opening.

$0.06 \mathrm{~mm}^{2}$ (Fig. 8). By $46 \mathrm{~h}$ post hatch, the yolk sac was almost absorbed, the eyes started to show visible pigmentation and mouth opened with a mouth gape of around $228.10 \pm 1.31 \mu \mathrm{m}$ (Fig. 9). Enriched rotifers screened with $100 \mu \mathrm{m}$ and copepod nauplii were utilized 


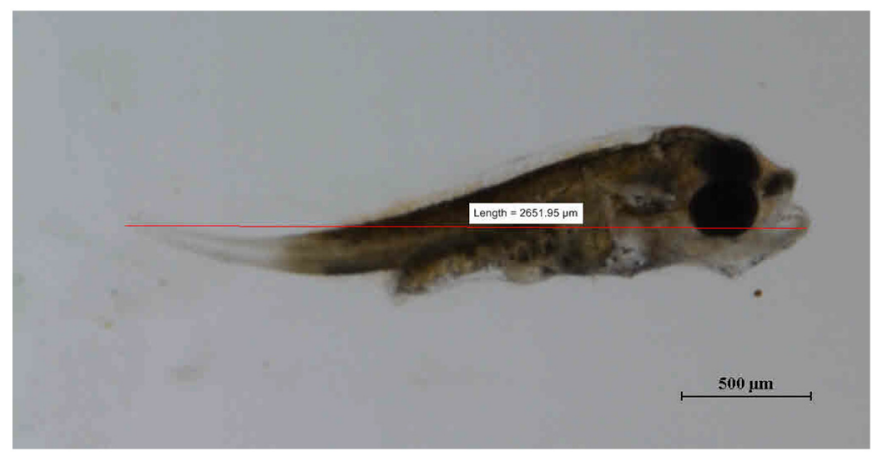

Fig. 10. Third day post hatched larvae with no yolk sac.

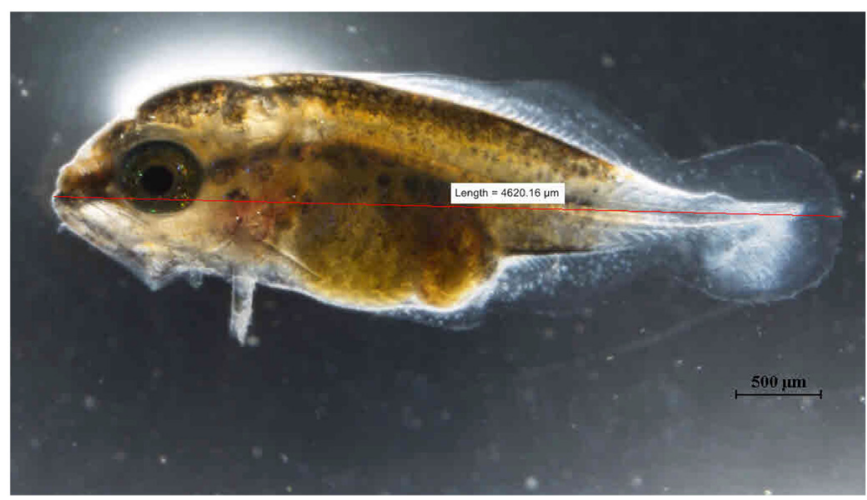

Fig. 11. Sixth day post hatched larvae with bulged stomach.

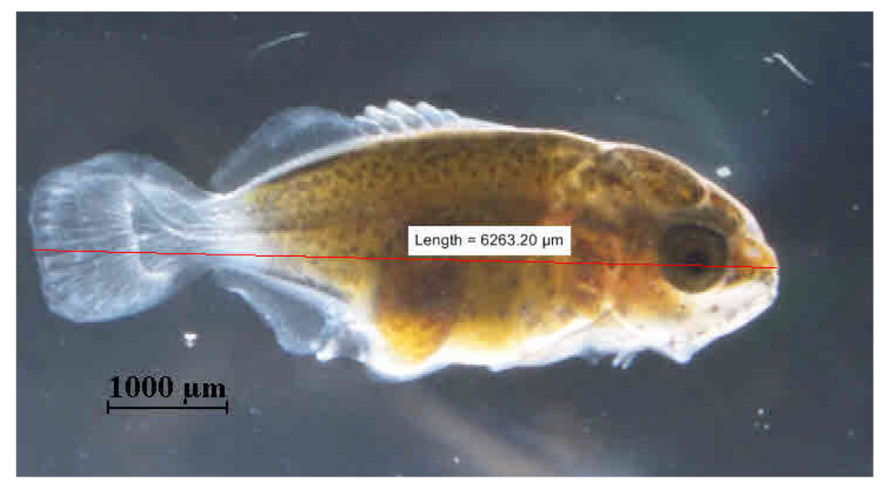

Fig. 12. Eight day post hatched larvae showing appearance of the dorsal, caudal and pelvic fins.

as the initial feed during this stage. The yolk sac was completely absorbed by $3^{\text {rd }} \mathrm{DPH}$, when the larval body length was about $2.66 \pm 0.03 \mathrm{~mm}$ (Fig. 10). Larval body length reached about $4.64 \pm 0.3 \mathrm{~mm}$ by $6^{\text {th }} \mathrm{DPH}$, by this time, amount as well as size of rotifers given was increased to satisfy the consumption demand (Fig. 11). Larval body length reached about $6.35 \pm 0.02 \mathrm{~mm}$ by $8^{\text {th }}$ $\mathrm{DPH}$, at this stage, appearance of the dorsal, caudal and pelvic fins began (Fig. 12). At this stage, enriched Artemia nauplii were fed to the larvae for faster growth. The larvae grew to $9.04 \pm 0.06 \mathrm{~mm}$ by $10^{\text {th }}$ $\mathrm{DPH}$, by which time all fin types were well demarcated. Melanin pigmentation started from embryo development onwards and became intense as the larvae grew. Therefore, larvae body colour was dark till $10^{\text {th }} \mathrm{DPH}$ (Fig. 13). Artificial formulated feed was fed to the larvae from $12^{\text {th }} \mathrm{DPH}$, when larval body length reached about $11.91 \pm 0.07 \mathrm{~mm}$. Larvae started metamorphosis by $17^{\text {th }} \mathrm{DPH}$ onwards, when larval body length reached $20.55 \pm 0.08 \mathrm{~mm}$ and metamorphosis was completed by $21^{\text {st }} \mathrm{DPH}$, when larvae had grown to $27.33 \pm 0.10 \mathrm{~mm}$. The larval body colour changed from dark to silvery on completion of

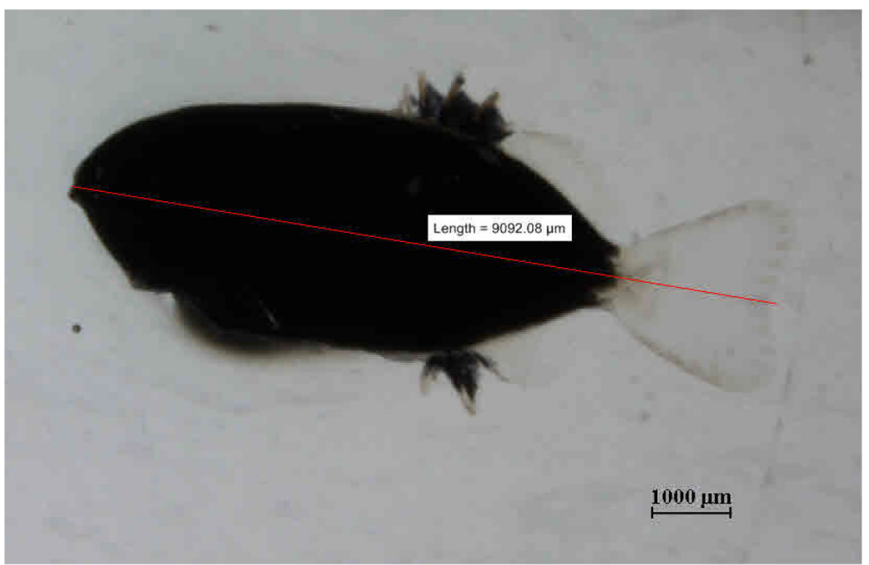

Fig. 13. Tenth day post hatched larvae showing maximum melanin pigmentation.

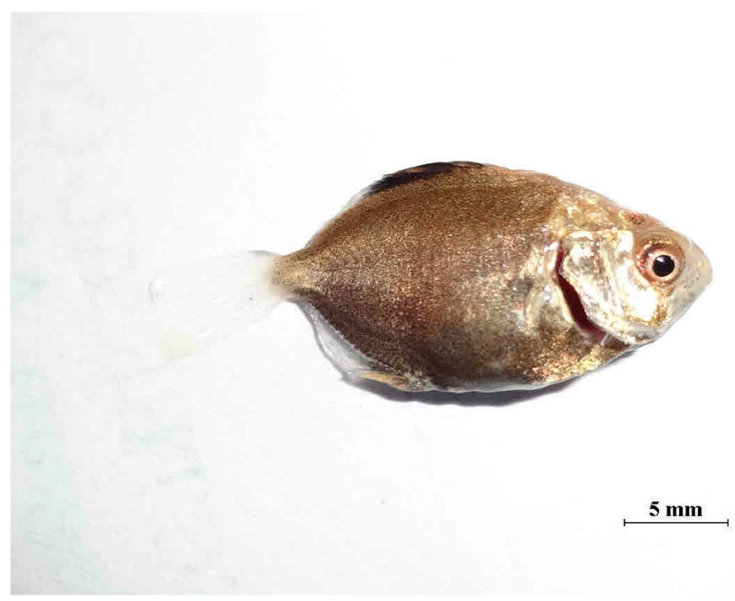

Fig. 14. Twenty first day post hatch juvenile showing silvery colour after completion of metamorphosis.

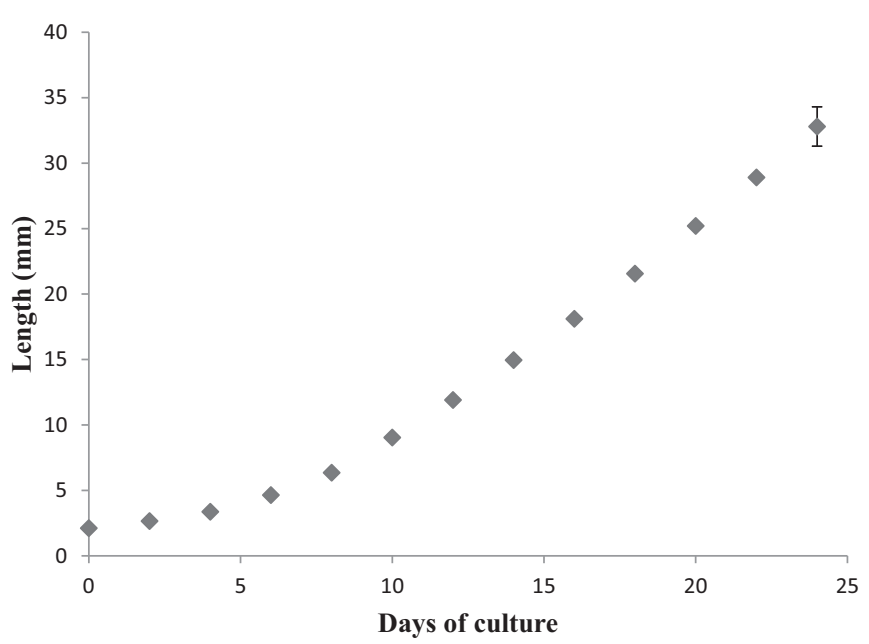

Fig. 15. Growth of Indian pompano larvae during captive larval rearing.

metamorphosis into juveniles (Fig. 14). The juveniles had developed the entire components of all fins and had started feeding on artificial pellets of $0.8 \mathrm{~mm}$.

Despite similarities in morphological development, the growth rate of Indian pompano larvae was higher than that reported for silver pompano, T. blochii (Abdul Nazar et al. 2012). The specific growth rate 


\begin{tabular}{|c|c|c|c|c|c|c|c|c|c|c|c|c|}
\hline Feed management & \multicolumn{12}{|c|}{\begin{tabular}{|l|l|l|l|l|l|l|l|l|l|l|l|l|l|}
0 & 1 & 2 & 3 & 4 & 5 & 6 & 7 & 8 & 9 & 10 & 11 & 12 & 13 \\
\end{tabular}} \\
\hline \multicolumn{13}{|l|}{ Microalgae $\left(10^{5} / \mathrm{ml}\right)$} \\
\hline \multicolumn{13}{|l|}{ Copepod Nauplii (2 nos $/ \mathrm{mll})$} \\
\hline \multicolumn{13}{|l|}{ Rotifers $(<100 \mu \mathrm{m})(10-15 \mathrm{nos} / \mathrm{ml})$} \\
\hline \multicolumn{13}{|l|}{ Rotifers (15-25 nos./ml) } \\
\hline \multicolumn{13}{|l|}{ Artemia $(1-2 \mathrm{nos} . / \mathrm{ml})$} \\
\hline \multicolumn{13}{|l|}{ Artificiall diet } \\
\hline \multicolumn{13}{|l|}{ Water management } \\
\hline \multicolumn{13}{|l|}{ Siphoning } \\
\hline \multicolumn{13}{|l|}{ Water exchange } \\
\hline$\approx 10 \% /$ day & & & & & & & & & & & & \\
\hline$\approx 20 \% /$ day & & & & & & & & & & & & \\
\hline$\sim 50 \% /$ day & & & & & & & & & & & & \\
\hline$\approx 100 \% /$ day & & & & & & & & & & & & \\
\hline
\end{tabular}

Fig. 16. Standardized feeding and water management protocol developed for larval rearing of Indian pompano.

estimated in the present experiment was $11.4 \%$ per day during larval rearing, which was found to be higher than the reported specific growth rate per day (8\%) of T. blochii (Abdul Nazar et al. 2012). The length of the newly hatched larvae was $2.12 \pm 0.02 \mathrm{~mm}$ which increased to $32.8 \pm 0.09 \mathrm{~mm}$ after 24 days of culture (Fig. 15). On the other hand $T$. blochii attained only $15.50 \mathrm{~mm}$ from $2.1 \mathrm{~mm}$ after 25 days of culture (Abdul Nazer et al., 2012).

The larval rearing protocol developed for successful seed production is summarised in Fig. 16. Artificial lightening of 700-800 lx was provided to the tank by fixing fluorescent tube over the tank for duration of 14-16 h. Microalgae, Nannochloropsis oculata and Isochrysis galbana in 3:1 ratio @ $1 \times 10^{5}$ cells $/ \mathrm{ml}$ was found to be suitable for larval rearing of Indian pompano. The present study, during larval rearing, achieved an average survival rate of $21.53 \pm 1.45 \%$ till complete metamorphosis, which is the first record in T. mookalee. The average survival rate upto metamorphosis in various species of pompano used for aquaculture is around $20 \%$, depending upon the feeding protocol. Juniyanto et al. (2008) and Abdul Nazar et al. (2012) had reported $20-25 \%$ and $10-15 \%$ survival during the larval rearing of $T$. blochii. Main et al. (2005) reported 3\% and 23\% survival in T. carolinus when they were fed on $100 \%$ rotifers alone and on copepod with rotifers. In our experiment, larvae were initially fed on both copepod nauplii and rotifer which would have helped in achieving a higher initial survival and thus an overall survival rate of $21.53 \pm 1.45 \%$ upto metamorphosis. The critical period for larval survival in Indian pompano was between $5^{\text {th }}$ and $6^{\text {th }} \mathrm{DPH}$, when the larval mortality was observed in rotifer fed larvae. However this was overcome significantly after feeding the larvae with copepod nauplii. In these rearing experiments, a systematic and overlapping regime of live foods beginning from copepod nauplii and rotifer to Artemia and artificial pellets were utilized. The adequate supply of live foods for meeting nutritional requirements of larvae, as has been developed in the present experiment, holds key for improving production of T. mookalee larvae in future.

\section{Conclusion}

The present study showed that $T$. mookalee can be domesticated in captive conditions with subsequent development of functional mature broodstock which undergoes final oocyte maturation for captive seed production. The potential of being induced for spawning in captivity and larval rearing with a survival rate of $21.53 \%$ makes Indian pompano an excellent candidate species for aquaculture. This report forms the first record of gonadal maturation, broodstock development, induced breeding and larval rearing of this species under captivity.

\section{Acknowledgments}

The authors are thankful to ICAR, Govt. of India, New Delhi for financial support. Thanks are due to Dr. Imelda Joseph, HoD, Mariculture Division, CMFRI and Dr. G. Gopakumar, Former Head, Mariculture Division, ICAR-CMFRI for the continuous support and encouragement extended during the period of study.

\section{References}

Abdul Nazar, A.K., Jayakumar, R., Tamilmani, G., Sakthivel, M., Kalidas, C., Ramesh Kumar, P., Anbarasu, M., Sirajudeen, S., Balamurugan, V., Jayasingh, M., Gopakumar, G., 2012. Larviculture and seed production of the silver pompano, Trachnotus blochii (Lacepede, 1801) for the first time in India. Indian J. Fish. 59 (3), 83-87.

APHA, 1998. Standard Methods for the Examination of Water and Wastewater, 20th edn. American Public Health Association, New York.

Chang, S.L., 1993. The breeding and culture of pompano (Trachinotus blochii). Fu-So Mag. Ser. 7 (1), 61-65.

Cheng, S.C., 1990. Reports on the artificial propagation of pompano (Trachinotus blochii). Fish World 4, 140-146.

Gopakumar, G., Abdul Nazar, A.K., Jayakumar, R., Tamilmani, G., Kalidas, C., Sakthivel, M., Rameshkumar, P., Hanumantarao, G., Premjothi, R., Balamurugan, V., Ramkumar, B., Jayasingh, M., Syda Rao, G., 2012. Broodstock development through regulation of photoperiod and controlled breeding of silver pompano, Trachinotus blochii (Lacepede, 1801) in India. Indian J. Fish. 59 (1), 53-57.

Hoff, F.H., Rowell, C., Pulver, T., 1972. Artificially induced spawning of the Florida pompano under controlled conditions. Proc. World Maricult. Soc. 3, 53-64.

Hoff, F.H., Pulver, T., Mountain, J., 1978a. Conditioning of Florida pompano (Trachinotus carolinus) for continous spawning. Proc. World Maricult. Soc. 9, 299-309.

Hoff, F.H., Mountain, J., Frakes, T., Halcott, K., 1978b. Spawning, oocytes development and larval rearing of the Florida pompano (Trachinotus carolinus). Proc. World Maricult. Soc. 9, 279-297.

Juniyanto, N.M., Akbar, S., Zakimin, 2008. Breeding and seed production of silver pompano (Trachinotus blochii, Lacepede) at the mariculture development center of Batam. Aquacult. Asia Mag. 13 (2), 46-48.

Lemos, V.M., Varela Jr., A.S., Velasco, G., Vieira, J.P., 2011. The reproductive biology of the plata pompano, Trachinotus marginatus (Teleostei: Carangidae), in southern Brazil. Zoologia 28 (5), 603-609.

Main, K.L., Marcus, N., Brown, C., 2005. Developing marine fish hatchery and nursery culture to expand Florida's aquaculture industry, year $2.4^{\text {th }}$ Quartely progress report, mote technical report 1028. https://dspace.mote.org/dspace/bitstream/2075/160/ 4/MTR\%201028.pdf.

Mcmaster, M.F., Kloth, T.C., Coburn, J.F., 2003. Prospects for commercial pompano mariculture - 2003. Aquaculture Am. 2003. http//www.mariculturetechnology. com/AquacultureAmerica03.pdf.

Peter, R.E., Lin, H.R., Van der Kraak, G., Little, M., 1993. Releasing hormones, dopamine antagonists and induced spawning. In: Muir, J.F., Roberts, R.J. (Eds.), Recent Advances in Aquaculture. Blackwell Scientific Publications Ltd, Oxford, pp. 25-30.

Randall, J.E., 1995. Coastal Fishes of Oman. University of Hawaii Press, Honolulu, Hawaii (439 p).

Ranjan, R., Abdul Nazar, A.K., Jayakumar, R., 2017a. Trachinotus mookalee Cuvier, 1832. In: Ranjan, R., Muktha, M., Ghosh, S., Gopalakrishnan, A., Gopakumar, G. (Eds.), Prioritized Species for Mariculture in India. ICAR-CMFRI, Kochi, pp. 21-25.

Ranjan, R., Megarajan, S., Xavier, B., Dash, B., Shosh, S., Muktha, M., Edward, L.L., 2017b. Conditioning, maturation and year-round natural spawning of orange-spotted 
grouper, Epinephelus coioides (Hamilton, 1822), in re-circulating aquaculture system. Aquac. Res. 48, 5864-5873.

Smith-Vaniz, W.F., 1984. Carangidae, in: Fischer, W., Bianchi, G., (Eds.), FAO species identification sheets for fishery purposes. Western Indian Ocean fishing area 51 . Vol. 1. [Pag. Var.]. FAO, Rome.

Weirich, C.R., Riley, K.L., 2007. Volitional spawning of Florida pompano, Trachinotus carolinus, induced via administration of gonadotropin releasing hormone analogue (GnRHa). J. Appl. Aquacul. 19 (3), 47-60.

Zohar, Y., 1988. Gonadotropin releasing hormone in spawning induction in teleosts: basic and applied considerations. In: Zohar, Y., Breton, B. (Eds.), Reproduction in Fish: Basic and Applied Aspects in Endocrinology and Genetics. INRA Press, Paris, pp. 47-62.

Zohar, Y., 1989a. Fish reproduction: its physiology and artificial manipulation. In: Shilo, M., Sarig, S. (Eds.), Fish Culture in Warm Water Systems: Problems and Trends. CRC Press, Boca Raton, pp. 65-119.

Zohar, Y., 1989b. Endocrinology and fish farming: aspects in reproduction growth, and smoltification. Fish Phy. Biochem. 7, 395-405. 